\title{
Correlations of subjectively assessed fleece and conformation traits with production and reproduction in Afrino sheep
}

\author{
M. A. Snyman ${ }^{\#}$ and W. J. Olivier \\ Grootfontein Agricultural Development Institute, Private Bag X529, Middelburg Cape 5900, South Africa
}

\begin{abstract}
Data used for this study were collected on the Carnarvon Afrino flock from 1986 to 1998, and include data records on several subjectively assessed traits, body weight and fleece traits of 3291 animals, the progeny of 127 sires and 772 dams. Reproduction data of 686 ewes born from 1986 to 1997 were also included. The heritabilities of and genetic and phenotypic correlations among the subjectively assessed traits were estimated, as well as the genetic and phenotypic correlations of these traits with body weight, objective fleece traits and reproduction. Heritability estimates for the various subjectively assessed traits ranged from $0.06 \pm 0.02$ for straightness of the top line to $0.51 \pm 0.04$ for softness of fleece. Positive genetic correlations, ranging from $0.33 \pm 0.18$ to $0.80 \pm 0.06$ were estimated amongst the conformation traits head, front quarters, top line and hocks. High genetic correlations were estimated among the subjectively assessed fleece traits and fibre diameter, where animals with lower fibre diameter had softer fleeces, better crimp definition, their fleeces were more even, less dense and had higher creeping belly scores (the extent to which belly wool tends to creep up the side into the fleece). Estimated genetic correlations between the subjectively assessed fleece traits and reproduction were variable in sign and magnitude. The most important of these is the unfavourable genetic correlation $(-0.33 \pm 0.23)$ between creeping belly and reproduction. The conformation traits had moderate to high genetic correlations with body weight at all ages. Of the subjectively assessed fleece traits, creeping belly score had the highest genetic correlation with body weight, ranging from $-0.26 \pm 0.10$ for weaning weight to $-0.38 \pm 0.07$ for 15 -month body weight. No noteworthy phenotypic correlations were discernable between the reproductive traits and any of the subjectively assessed traits. Of the objective fleece traits, only fibre diameter had some significant phenotypic correlations with the subjectively assessed fleece traits. These were similar in sign, but smaller in magnitude than the corresponding genetic correlations. It is concluded that, with the exception of two or three traits, the subjectively assessed traits would not be negatively influenced when selection is based on the economically important production traits. It is, however, important that selection priorities be based on economic values of the traits.
\end{abstract}

Keywords: Correlations, linearly assessed type traits, wool traits, body weight, reproduction

\#Corresponding author: E-mail: grethas@ndagadi.agric.za

\section{Introduction}

The ultimate aim of sheep breeding research is to provide estimates of the parameters required to construct a genetic improvement plan leading to improved viability, productivity and profitability of the specific enterprise. In numerous studies in the past, genetic parameters for objective production traits have been estimated (See Fogarty, 1995 and Snyman et al., 1995 for reviews). Recently, emphasis was also placed on reproduction, for which genetic parameters for various components of reproduction have been published (Fogarty et al., 1994; Snyman et al., 1997, 1998a,b,c; Olivier et al., 2001). In practice, however, considerable emphasis is placed on subjectively assessed conformation and fleece traits in selecting breeding sires and dams. In many instances, animals are culled on the basis of these traits, but at the expense of the economically important traits such as reproduction.

Phenotypic correlations between some subjectively assessed fleece traits and wool production in Merino sheep are available (Cloete et al., 1992; Crook et al., 1994; Lewer et al., 1995; Olivier et al., 1997). However, very little is known regarding the heritability (Lewer et al., 1995; Swan et al., 1997; Groenewald et al., 1999) and genetic relationships of these subjectively assessed traits with the economically important traits such as body weight, fleece weight and fibre diameter (Lewer et al., 1995; Hill et al., 1997; Swan et al., 1997). Furthermore, no genetic or phenotypic correlations between subjectively assessed traits and reproductive performance could be found in the literature. 
Several conformation and fleece traits were assessed on a linear scale on Afrino sheep. The heritabilities of, and genetic and phenotypic correlations among these traits were estimated, as well as the genetic and phenotypic correlations of these traits with body weight, objective fleece traits and reproduction. This was done in an attempt to determine how selection emphasis on the subjectively assessed traits in the selection programme of Afrino, as well as other white woolled breeds, would influence genetic progress in the economically important production and reproduction traits.

\section{Material and methods}

Data used for this study were collected on the Carnarvon Afrino flock. Details of the management and selection procedures followed in the flock have been discussed by Snyman et al. (1995a). These include data records on several subjectively assessed traits, body weight and fleece traits, as well as reproduction data. At 14 16 months of age, 13 subjectively assessed fleece and conformation traits were assessed on a linear scale ranging from 1 to 50 in all animals. These traits were general head conformation, softness of face covering, extent of pigmentation in the face and on the ears, softness of fleece, crimp definition, density of fleece, evenness of fleece (in terms of crimp frequency - which was taken as an indication of fibre diameter, and staple length), creeping belly (extent to which belly wool creeps up the sides), front quarter, straightness of the top line, hocks, front and hind pasterns. The scale of assessment, similar to the one described by Olivier et al. (1987) for Merino sheep, for the various traits is summarized in Table 1. These data were available for 3291 animals, the progeny of 127 sires and 772 dams, born from 1986 to 1998 in the Carnarvon Afrino flock.

Data records on weaning weight, body weight at 9- and 15-months of age, as well as clean fleece weight (corrected to a 12 month wool growth period), fibre diameter, clean yield and staple length measured at 15 months of age were also available for the same animals.

Table 1 Linear scale for assessment of subjectively assessed fleece and conformation traits in Afrino sheep

\begin{tabular}{llll}
\hline & \multicolumn{3}{c}{ Scale of assessment $^{\text {a }}$} \\
\hline Conformation traits : & $\mathbf{1}$ & $\mathbf{2 5}$ & $\mathbf{5 0}$ \\
General head conformation (HEAD) & Poor & Average & Ideal \\
Front quarters (FQRT) & Poor & Average & Ideal \\
Top line (TOPL) & Poor & Average & Ideal \\
Hocks (HOCK) & Poor & Average & Ideal \\
Front pasterns (FPAS) & Poor & Average & Ideal \\
Hind pasterns (HPAS) & Poor & Average & Ideal
\end{tabular}

\section{Other traits :}

$\begin{array}{llll}\text { Softness of face (FACE) } & \text { Hard } & \text { Average } & \text { Very soft } \\ \text { Pigmentation (PIGM) } & \text { None } & \text { Ideal } & \text { Excessive }\end{array}$

\section{Fleece traits :}

\begin{tabular}{llll} 
Softness of fleece (SOFT) & Hard & Average & Soft \\
Crimp definition (CRIM) & Poor & Average & Ideal \\
Density of fleece (DENS) & Poor & Average & Ideal \\
Evenness of fleece (EVEN) & Uneven & Average & No variation \\
Creeping belly (CBEL) & High up the sides & Average & None \\
\hline With the exception of pigmentation) $: 1-10=$ Poor; $11-20=$ Below average; $21-30=$ Average; \\
$-40=$ Above average; $41-50=$ Excellent
\end{tabular}

Reproduction data of 686 ewes born from 1986 to 1997 used for the study, include lifetime number of lambs born, lifetime number of lambs weaned and lifetime total weight of lamb weaned. Total weight $(\mathrm{kg})$ of lamb weaned per ewe per year was calculated as follows (Snyman et al., 1997): Firstly, within each lambing 
season, weaning weight for all lambs was corrected to 120 days, followed by least-squares corrections for sex of the lamb. No corrections were made for birth status. Secondly, the corrected weights of all the lambs produced by each ewe in each lambing season were added together, in order to obtain total weight of lamb weaned produced in a specific season. To obtain lifetime total weight of lamb weaned, total weight of lamb weaned per season were added together for all lambing opportunities a ewe had in the flock. Total number of lambs born and weaned per lifetime was calculated by adding all lambs born and weaned per ewe over her lifetime in the flock. The number of lambing opportunities for the ewes in the data set ranged from one to six, with an average of three lambing opportunities per ewe.

Heritability estimates for body weight and fleece traits (Snyman et al., 1995b) and the reproduction traits (Snyman et al., 1997), as well as the correlations among these traits (Snyman et al., 1998c) for the Carnarvon Afrino flock have already been reported. Therefore, for the purpose of this study, heritability estimates will only be estimated for the various subjectively assessed traits. Genetic and phenotypic correlations between these traits and objectively measured body weight, fleece traits and reproduction will also be estimated. Least square means and coefficients of variation for the various traits were obtained by fitting linear models, including fixed effects for year of birth, rearing status and sex of the animal, as well as age of the animal and age of dam (Littell et al., 1991).

Variance components and heritability estimates were obtained by fitting single trait animal models using the ASREML programme (Gilmour et al., 1997). Models including both direct as well as maternal genetic and permanent environmental effects were tested beforehand. Neither maternal genetic nor permanent environmental effects had any significant influence on any of the subjectively assessed traits. Therefore, models including only direct additive effects were applied for these traits. The fixed part of the models included fixed effects for year of birth, rearing status and sex of the animal, as well as age of the animal (linear) and age of dam (quadratic).

Covariance components among traits were obtained by fitting bi-variate animal models using the ASREML programme (Gilmour et al., 1997). Details regarding model specification for body weight and fleece traits can be obtained from Snyman et al. (1995b). For the analyses of lifetime reproduction traits, the birth year of the ewe, as well as her number of lambing opportunities were included as fixed effects in the model (Snyman et al., 1997). Effects included for analyses of the subjectively assessed traits were the same as those included for estimation of heritability.

\section{Results}

Least square means and coefficient of variation (CV) for all traits are given in Table 2. From Tables 1 and 2 it is obvious that animals in the Carnarvon Afrino flock attained above average scores for all the subjectively assessed traits, with the exception of CRIM, which received an average score. An ideal score was given for PIGM. Coefficients of variation for most of the subjectively assessed traits were between $10 \%$ and $22 \%$, similar to most other biological traits. The highest CV's were obtained for PIGM (33\%), CRIM (34\%) and CBEL (29\%).

Heritability estimates of and genetic and phenotypic correlations among the subjectively assessed conformation and fleece traits are summarised in Table 3.

Heritability estimates for the various subjectively assessed traits ranged from low $(0.06 \pm 0.02$ for TOPL and $0.08 \pm 0.03$ for HPAS) and moderate $(0.21 \pm 0.04$ for FPAS, $0.22 \pm 0.03$ for FQRT, $0.23 \pm 0.04$ for FACE, $0.26 \pm 0.04$ for DENS, $0.28 \pm 0.04$ for EVEN and $0.32 \pm 0.04$ for HEAD) to high $(0.36 \pm 0.04$ for HOCK, $0.3 \pm 0.04$ for CBEL, $0.47 \pm 0.04$ for CRIM, $0.50 \pm 0.04$ for PIGM and $0.51 \pm 0.04$ for SOFT). These heritabilities accord well with those estimated by Groenewald et al. (1999) for South African Merino sheep.

Many of the genetic correlations among these traits are low or negligible and therefore of no economic importance. The only genetic correlations of significance among the conformation traits are those among HEAD, FQRT, TOPL and HOCK, which are all positive and ranged from 0.30 to 0.80 .

There were also no noteworthy genetic correlations between the conformation and the fleece traits, which ranged from -0.35 to 0.14 . CBEL score was negatively correlated with all the conformation traits $(-0.23$ to -0.32$)$, which implies that animals with the better conformation had a lower creeping belly score. High genetic correlations were estimated among the subjectively assessed fleece traits, with the exception of DENS and EVEN. Generally, animals with softer fleeces had better crimp definition, their fleeces were more even, less dense and they had lower creeping belly scores.

The only noteworthy phenotypic correlations were that of $0.45 \pm 0.02$ estimated between HEAD and FQRT, and those among the fleece traits. In general, the phenotypic correlations among the fleece traits were 
similar in sign, but lower in magnitude, than the corresponding genetic correlations.

Genetic correlations of reproduction, body weight and fleece traits with the various subjectively assessed conformation and fleece traits are summarised in Table 4.

Due to the limited number of reproductive records, standard errors for the genetic correlations were relatively high. These results should therefore be regarded merely as an indication of whether positive or negative relationships exist between traits where relatively large correlations were estimated. High positive genetic correlations were estimated between the reproductive traits and HEAD, FQRT and FACE respectively. Hocks and pasterns had low positive genetic correlations with the reproduction traits, ranging from $0.01 \pm 0.34$ to $0.28 \pm 0.29$, while negative genetic correlations were estimated between reproduction traits and TOPL. The genetic correlations were variable in sign and magnitude between the fleece and reproduction traits.

Table 2 Least-square means and coefficient of variation (CV) for all traits analysed

\begin{tabular}{lcc}
\hline & MEAN & CV (\%) \\
\hline General head conformation (HEAD) & 35.8 & 16.4 \\
Forequarters (FQRT) & 35.8 & 12.0 \\
Top line (TOPL) & 35.4 & 11.3 \\
Hocks (HOCK) & 35.2 & 16.6 \\
Front pasterns (FPAS) & 36.6 & 13.4 \\
Hind pasterns (HPAS) & 38.9 & 9.9 \\
Softness of face covering (FACE) & 35.5 & 15.1 \\
Pigmentation (PIGM) & 23.6 & 32.9 \\
Softness of fleece (SOFT) & 33.1 & 22.3 \\
Crimp definition (CRIM) & 27.1 & 33.7 \\
Density of fleece (DENS) & 34.8 & 16.1 \\
Evenness of fleece (EVEN) & 34.2 & 17.9 \\
Creeping belly (CBEL) & 38.7 & 28.9 \\
Weaning weight (kg) (WW) & 27.8 & 12.0 \\
9-month body weight (kg) (W9) & 43.3 & 9.4 \\
15-month body weight (kg) (W15) & 55.0 & 8.7 \\
15-month clean fleece weight (kg) (CFW) & 2.0 & 17.8 \\
Fibre diameter ( $\mu$ m) (FD) & 20.7 & 6.4 \\
Clean yield (\%) (CY) & 60.13 & 11.0 \\
Staple length (mm) (SL) & 79.6 & 15.3 \\
Total weight of lamb weaned (kg) (TWW) & 119.0 & 30.3 \\
Number of lambs born (NLB) & 4.3 & 30.0 \\
Number of lambs weaned (NLW) & 3.9 & 33.1 \\
\hline
\end{tabular}

As could be expected, the conformation traits generally had moderate to high genetic correlations with body weight at all ages. Of the subjectively assessed fleece traits, CBEL had the largest genetic correlations with body weight, ranging from $-0.26 \pm 0.10$ for WW to $-0.38 \pm 0.07$ for W15.

Apart from the negative correlation between clean fleece weight and HOCK $(-0.45 \pm 0.07)$, there were no noteworthy correlations between the conformation traits and the objective fleece traits. Softness of face cover (FACE) had favourable relationships with CFW, MFD, CY and SL, while the softer fleeces also had a genetically lower fibre diameter $\left(r_{\mathrm{g}}=-0.80 \pm 0.03\right)$. Genetically, fleeces with lower fibre diameter had better crimp definition, were less dense and more even, and had lower creeping belly scores. Furthermore, fleeces with higher creeping belly scores had higher clean yields $(0.41 \pm 0.06)$.

Phenotypic correlations of reproduction, body weight and fleece traits with the various subjectively assessed conformation and fleece traits are summarised in Table 5. 
Table 3 Heritability estimates (diagonal, bold face) (s.e.) of, and genetic and phenotypic correlations ${ }^{\text {a }}$ (s.e.) among various subjectively assessed conformation and fleece traits ${ }^{\mathrm{b}}$

\begin{tabular}{|c|c|c|c|c|c|c|c|c|c|c|c|c|c|}
\hline & HEAD & FQRT & TOPL & HOCK & FPAS & HPAS & FACE & PIGM & SOFT & CRIM & DENS & EVEN & CBEL \\
\hline HEAD & $0.32 \pm 0.04$ & $0.80 \pm 0.06$ & $0.33 \pm 0.18$ & $0.42 \pm 0.09$ & $0.15 \pm 0.12$ & $0.14 \pm 0.16$ & $0.04 \pm 0.11$ & $0.12 \pm 0.08$ & $-0.03 \pm 0.09$ & $0.00 \pm 0.09$ & $0.00 \pm 0.11$ & $-0.15 \pm 0.12$ & $-0.25 \pm 0.09$ \\
\hline FQRT & $0.45 \pm 0.02$ & $0.22 \pm 0.03$ & $0.53 \pm 0.19$ & $0.65 \pm 0.09$ & $-0.04 \pm 0.13$ & $-0.18 \pm 0.16$ & $-0.03 \pm 0.12$ & $0.12 \pm 0.09$ & $-0.24 \pm 0.09$ & $-0.11 \pm 0.09$ & $0.14 \pm 0.11$ & $-0.27 \pm 0.12$ & $-0.23 \pm 0.09$ \\
\hline TOPL & $0.11 \pm 0.02$ & $0.11 \pm 0.02$ & $0.06 \pm 0.02$ & $0.64 \pm 0.16$ & $0.18 \pm 0.20$ & $0.10 \pm 0.25$ & $-0.14 \pm 0.21$ & $-0.02 \pm 0.17$ & $-0.35 \pm 0.19$ & $0.12 \pm 0.08$ & $-0.18 \pm 0.22$ & $-0.17 \pm 0.21$ & $-0.32 \pm 0.17$ \\
\hline HOCK & $0.15 \pm 0.02$ & $0.14 \pm 0.02$ & $0.19 \pm 0.02$ & $0.36 \pm 0.04$ & $0.02 \pm 0.10$ & $0.00 \pm 0.14$ & $-0.43 \pm 0.09$ & $-0.04 \pm 0.08$ & $-0.29 \pm 0.08$ & $-0.04 \pm 0.08$ & $0.05 \pm 0.10$ & $-0.23 \pm 0.10$ & $-0.23 \pm 0.08$ \\
\hline FPAS & $0.04 \pm 0.02$ & $0.04 \pm 0.02$ & $0.04 \pm 0.02$ & $0.01 \pm 0.02$ & $0.21 \pm 0.04$ & & $0.06 \pm 0.12$ & $0.05 \pm 0.10$ & $-0.02 \pm 0.11$ & $0.03 \pm 0.11$ & $-0.08 \pm 0.13$ & $0.10 \pm 0.13$ & $-0.25 \pm 0.10$ \\
\hline HPAS & $0.05 \pm 0.02$ & $0.01 \pm$ & $0.00 \pm 0.02$ & $0.03 \pm 0.02$ & & $0.08 \pm 0.03$ & $-0.29 \pm 0.15$ & $0.06 \pm 0.13$ & $0.14 \pm 0.14$ & $0.04 \pm 0.14$ & $-0.35 \pm 0.16$ & $0.00 \pm 0.17$ & $-0.26 \pm 0.13$ \\
\hline FACE & $0.17 \pm 0.02$ & $0.08 \pm 0.02$ & $0.01 \pm 0.02$ & $-0.06 \pm 0.02$ & $0.02 \pm 0.02$ & $0.00 \pm 0.02$ & $0.23 \pm 0.04$ & $0.10 \pm 0.09$ & $0.20 \pm 0.09$ & $0.05 \pm 0.10$ & $-0.05 \pm 0.11$ & $0.18 \pm 0.12$ & $0.03 \pm 0.09$ \\
\hline PIGM & $0.09 \pm 0.02$ & $0.05 \pm 0.02$ & $0.03 \pm 0.02$ & $-0.02 \pm 0.02$ & $0.01 \pm 0.02$ & $0.02 \pm 0.02$ & $0.05 \pm 0.02$ & $0.50 \pm 0.04$ & $-0.09 \pm 0.07$ & $-0.05 \pm 0.07$ & $-0.03 \pm 0.09$ & $0.07 \pm 0.10$ & $0.09 \pm 0.07$ \\
\hline SOFT & $-0.01 \pm 0.02$ & $-0.07 \pm 0.02$ & $-0.04 \pm 0.02$ & $-0.09 \pm 0.02$ & $-0.01 \pm 0.02$ & $-0.01 \pm 0.02$ & $0.11 \pm 0.02$ & $0.00 \pm 0.02$ & $0.51 \pm 0.04$ & $0.80 \pm 0.03$ & $-0.64 \pm 0.06$ & $0.81 \pm 0.05$ & $-0.52 \pm 0.05$ \\
\hline CRIM & $0.01 \pm 0.02$ & $-0.04 \pm 0.02$ & $-0.02 \pm 0.02$ & $-0.04 \pm 0.02$ & $0.02 \pm 0.02$ & $0.00 \pm 0.02$ & $0.04 \pm 0.02$ & $0.03 \pm 0.02$ & $0.62 \pm 0.01$ & $0.47 \pm 0.04$ & $-0.61 \pm 0.07$ & $0.62 \pm 0.07$ & $-0.67 \pm 0.05$ \\
\hline DENS & $0.05 \pm 0.02$ & $0.11 \pm 0.02$ & $0.01 \pm 0.02$ & $0.09 \pm 0.02$ & $0.02 \pm 0.02$ & $-0.03 \pm 0.02$ & $-0.05 \pm 0.02$ & $-0.02 \pm 0.02$ & $-0.40 \pm 0.02$ & $-0.36 \pm 0.02$ & $0.26 \pm 0.04$ & $0.02 \pm 0.12$ & $0.51 \pm 0.07$ \\
\hline EVEN & $-0.08 \pm 0.03$ & $-0.11 \pm 0.02$ & $-0.05 \pm 0.02$ & $-0.10 \pm 0.02$ & $0.04 \pm 0.02$ & $-0.03 \pm 0.02$ & $0.04 \pm 0.02$ & $0.01 \pm 0.02$ & $0.32 \pm 0.02$ & $0.40 \pm 0.02$ & $0.05 \pm 0.02$ & $0.28 \pm 0.04$ & $-0.27 \pm 0.10$ \\
\hline CBEL & $-0.06 \pm 0.02$ & $0.00 \pm 0.02$ & $0.03 \pm 0.02$ & $0.01 \pm 0.02$ & $-0.01 \pm 0.02$ & $-0.01 \pm 0.02$ & $0.00 \pm 0.02$ & $0.00 \pm 0.02$ & $-0.35 \pm 0.02$ & $-0.45 \pm 0.02$ & $0.31 \pm 0.02$ & $-0.15 \pm 0.03$ & $0.37 \pm 0.04$ \\
\hline
\end{tabular}

${ }^{\mathrm{a}}$ Genetic correlations above diagonal and phenotypic correlations below diagonal

${ }^{\mathrm{b}}$ See Table 2 for an explanation of the traits 
Table 4 Genetic correlations (s.e.) of reproduction, body weight and fleece traits with various subjectively assessed conformation and fleece traits ${ }^{\text {a }}$

\begin{tabular}{|c|c|c|c|c|c|c|c|c|c|c|}
\hline & TWW & NLB & NLW & $\overline{W W}$ & W9 & W15 & CFW & MFD & $\mathrm{CY}$ & SL \\
\hline HEAD & $0.79 \pm 0.24$ & $0.45 \pm 0.21$ & $0.57 \pm 0.21$ & $0.85 \pm 0.05$ & $0.85 \pm 0.04$ & $0.82 \pm 0.05$ & $-0.18 \pm 0.08$ & $-0.05 \pm 0.07$ & $-0.07 \pm 0.08$ & $-0.05 \pm 0.10$ \\
\hline FQRT & $0.88 \pm 0.35$ & $0.47 \pm 0.31$ & $0.27 \pm 0.35$ & $0.70 \pm 0.08$ & $0.81 \pm 0.05$ & $0.87 \pm 0.04$ & $-0.02 \pm 0.09$ & $0.09 \pm 0.08$ & $0.21 \pm 0.09$ & $-0.07 \pm 0.11$ \\
\hline TOPL & $-0.42 \pm 0.36$ & $-0.14 \pm 0.30$ & $-0.34 \pm 0.30$ & $0.30 \pm 0.21$ & $0.37 \pm 0.18$ & $0.49 \pm 0.18$ & $-0.25 \pm 0.17$ & $0.33 \pm 0.16$ & $-0.02 \pm 0.16$ & $0.34 \pm 0.17$ \\
\hline HOCK & $0.14 \pm 0.27$ & $0.10 \pm 0.22$ & $0.07 \pm 0.23$ & $0.50 \pm 0.10$ & $0.41 \pm 0.08$ & $0.41 \pm 0.08$ & $-0.45 \pm 0.07$ & $0.13 \pm 0.07$ & $-0.23 \pm 0.08$ & $-0.20 \pm 0.09$ \\
\hline FPAS & $0.20 \pm 0.32$ & $0.12 \pm 0.27$ & $0.11 \pm 0.27$ & $0.25 \pm 0.14$ & $0.17 \pm 0.11$ & $0.09 \pm 0.09$ & $-0.11 \pm 0.09$ & $-0.14 \pm 0.09$ & $0.09 \pm 0.09$ & $-0.29 \pm 0.11$ \\
\hline HPAS & $0.01 \pm 0.34$ & $0.28 \pm 0.29$ & $0.20 \pm 0.30$ & $0.32 \pm 0.16$ & $0.30 \pm 0.13$ & $0.30 \pm 0.13$ & $-0.09 \pm 0.13$ & $-0.23 \pm 0.12$ & $0.09 \pm 0.13$ & $-0.26 \pm 0.14$ \\
\hline FACE & $0.49 \pm 0.24$ & $0.30 \pm 0.22$ & $0.42 \pm 0.21$ & $-0.08 \pm 0.13$ & $0.02 \pm 0.10$ & $-0.10 \pm 0.10$ & $0.40 \pm 0.08$ & $-0.22 \pm 0.08$ & $0.26 \pm 0.08$ & $0.28 \pm 0.10$ \\
\hline PIGM & $-0.17 \pm 0.25$ & $-0.07 \pm 0.20$ & $-0.15 \pm 0.21$ & $0.13 \pm 0.10$ & $0.12 \pm 0.07$ & $0.08 \pm 0.07$ & $-0.02 \pm 0.06$ & $0.08 \pm 0.06$ & $-0.05 \pm 0.06$ & $0.04 \pm 0.08$ \\
\hline SOFT & $0.01 \pm 0.34$ & $-0.29 \pm 0.28$ & $-0.13 \pm 0.29$ & $-0.22 \pm 0.11$ & $-0.07 \pm 0.08$ & $-0.04 \pm 0.08$ & $0.02 \pm 0.07$ & $-0.80 \pm 0.03$ & $0.14 \pm 0.07$ & $0.00 \pm 0.09$ \\
\hline CRIM & $0.45 \pm 0.36$ & $0.06 \pm 0.30$ & $0.38 \pm 0.29$ & $-0.08 \pm 0.11$ & $0.06 \pm 0.08$ & $0.09 \pm 0.08$ & $-0.02 \pm 0.07$ & $-0.42 \pm 0.05$ & $-0.17 \pm 0.07$ & $-0.09 \pm 0.09$ \\
\hline DENS & $-0.08 \pm 0.53$ & $0.33 \pm 0.47$ & $-0.02 \pm 0.47$ & $0.11 \pm 0.13$ & $0.14 \pm 0.10$ & $0.02 \pm 0.09$ & $0.22 \pm 0.08$ & $0.48 \pm 0.06$ & $-0.04 \pm 0.09$ & $-0.38 \pm 0.09$ \\
\hline EVEN & $-0.50 \pm 0.33$ & $-0.31 \pm 0.27$ & $-0.32 \pm 0.27$ & $-0.08 \pm 0.14$ & $-0.04 \pm 0.10$ & $-0.14 \pm 0.10$ & $-0.02 \pm 0.09$ & $-0.57 \pm 0.07$ & $-0.22 \pm 0.09$ & $-0.19 \pm 0.10$ \\
\hline CBEL & $-0.33 \pm 0.23$ & $-0.13 \pm 0.19$ & $-0.25 \pm 0.20$ & $-0.26 \pm 0.10$ & $-0.31 \pm 0.08$ & $-0.38 \pm 0.07$ & $0.53 \pm 0.05$ & $0.41 \pm 0.05$ & $0.41 \pm 0.06$ & $0.27 \pm 0.08$ \\
\hline
\end{tabular}

${ }^{\mathrm{a}}$ See Table 2 for an explanation of the traits 
Table 5 Phenotypic correlations (s.e.) of reproduction, body weight and fleece traits with various subjectively assessed conformation and fleece traits ${ }^{\text {a }}$

\begin{tabular}{ccccccccccc}
\hline & TWW & NLB & NLW & WW & W9 & W15 & CFW & MFD & CY & SL \\
\hline HEAD & $0.17 \pm 0.04$ & $0.13 \pm 0.04$ & $0.13 \pm 0.04$ & $0.34 \pm 0.02$ & $0.43 \pm 0.02$ & $0.44 \pm 0.02$ & $0.07 \pm 0.02$ & $0.03 \pm 0.02$ & $-0.01 \pm 0.02$ & $0.07 \pm 0.02$ \\
FQRT & $0.12 \pm 0.04$ & $0.10 \pm 0.04$ & $0.08 \pm 0.04$ & $0.31 \pm 0.02$ & $0.40 \pm 0.02$ & $0.43 \pm 0.02$ & $0.14 \pm 0.02$ & $0.08 \pm 0.02$ & $0.03 \pm 0.02$ & $0.07 \pm 0.02$ \\
TOPL & $-0.01 \pm 0.05$ & $-0.01 \pm 0.05$ & $-0.03 \pm 0.05$ & $0.05 \pm 0.02$ & $0.06 \pm 0.02$ & $0.08 \pm 0.02$ & $0.03 \pm 0.02$ & $0.06 \pm 0.02$ & $0.04 \pm 0.02$ & $0.02 \pm 0.02$ \\
HOCK & $-0.01 \pm 0.04$ & $0.01 \pm 0.04$ & $-0.03 \pm 0.04$ & $0.14 \pm 0.02$ & $0.19 \pm 0.02$ & $0.18 \pm 0.02$ & $-0.15 \pm 0.02$ & $0.08 \pm 0.02$ & $-0.09 \pm 0.02$ & $-0.05 \pm 0.02$ \\
FPAS & $0.14 \pm 0.04$ & $0.12 \pm 0.04$ & $0.14 \pm 0.05$ & $0.04 \pm 0.02$ & $0.04 \pm 0.02$ & $0.01 \pm 0.02$ & $-0.01 \pm 0.02$ & $-0.01 \pm 0.02$ & $0.01 \pm 0.02$ & $0.00 \pm 0.02$ \\
HPAS & $0.05 \pm 0.04$ & $0.02 \pm 0.04$ & $0.03 \pm 0.05$ & $0.04 \pm 0.02$ & $0.04 \pm 0.02$ & $0.04 \pm 0.02$ & $0.00 \pm 0.02$ & $-0.04 \pm 0.02$ & $0.03 \pm 0.02$ & $0.00 \pm 0.02$ \\
FACE & $0.06 \pm 0.04$ & $0.05 \pm 0.04$ & $0.06 \pm 0.05$ & $0.03 \pm 0.02$ & $0.02 \pm 0.02$ & $0.00 \pm 0.02$ & $0.14 \pm 0.02$ & $-0.05 \pm 0.02$ & $0.07 \pm 0.02$ & $0.10 \pm 0.02$ \\
PIGM & $0.01 \pm 0.04$ & $0.01 \pm 0.04$ & $0.02 \pm 0.05$ & $0.04 \pm 0.02$ & $0.05 \pm 0.02$ & $0.05 \pm 0.02$ & $0.01 \pm 0.02$ & $0.02 \pm 0.02$ & $0.00 \pm 0.02$ & $0.01 \pm 0.02$ \\
SOFT & $0.00 \pm 0.04$ & $-0.01 \pm 0.04$ & $0.01 \pm 0.04$ & $-0.06 \pm 0.02$ & $-0.06 \pm 0.02$ & $-0.05 \pm 0.02$ & $0.00 \pm 0.02$ & $-0.50 \pm 0.02$ & $0.09 \pm 0.02$ & $0.05 \pm 0.02$ \\
CRIM & $-0.02 \pm 0.04$ & $-0.02 \pm 0.04$ & $0.01 \pm 0.04$ & $-0.01 \pm 0.02$ & $0.01 \pm 0.02$ & $0.02 \pm 0.02$ & $0.01 \pm 0.02$ & $-0.31 \pm 0.02$ & $-0.06 \pm 0.02$ & $0.00 \pm 0.02$ \\
DENS & $0.03 \pm 0.04$ & $0.04 \pm 0.04$ & $0.01 \pm 0.05$ & $0.08 \pm 0.02$ & $0.10 \pm 0.02$ & $0.06 \pm 0.02$ & $0.13 \pm 0.02$ & $0.29 \pm 0.02$ & $-0.09 \pm 0.02$ & $-0.16 \pm 0.02$ \\
EVEN & $-0.11 \pm 0.05$ & $-0.06 \pm 0.05$ & $-0.10 \pm 0.05$ & $-0.03 \pm 0.02$ & $-0.02 \pm 0.03$ & $-0.05 \pm 0.03$ & $0.00 \pm 0.02$ & $-0.26 \pm 0.02$ & $-0.06 \pm 0.02$ & $-0.09 \pm 0.02$ \\
CBEL & $-0.01 \pm 0.05$ & $0.01 \pm 0.04$ & $0.02 \pm 0.05$ & $-0.04 \pm 0.02$ & $-0.08 \pm 0.02$ & $-0.13 \pm 0.02$ & $0.29 \pm 0.02$ & $0.31 \pm 0.02$ & $0.19 \pm 0.02$ & $0.19 \pm 0.02$ \\
\hline a See Table 2 for an explanation of the traits & & & & & &
\end{tabular}

${ }^{\mathrm{a}}$ See Table 2 for an explanation of the traits 
From Table 5 it is evident that no noteworthy phenotypic correlations were discernable between the reproductive traits and any of the subjectively assessed traits. Furthermore, only HEAD and FQRT were positively correlated with body weight at all ages. Of the objective fleece traits, only MFD had some significant phenotypic correlations with the subjectively assessed fleece traits. These were similar in sign, but smaller in magnitude than the corresponding genetic correlations, where fleeces with lower fibre diameter had better crimp definition, were softer, less dense and more even, and had lower creeping belly scores.

\section{Discussion}

The breeding objectives for Afrino sheep are to increase total weight of lamb produced (TWW), increase the animal's own or direct growth performance (WW, W9), decrease or maintain fibre diameter (MFD) and at least maintain fleece weight (CFW). From the results of this study it is evident that general conformation of the head, forequarters, hocks and pastern joints will not deteriorate in a selection program which has increased TWW and increased body weight as its aim.

Softness of face cover (FACE) and the extent of pigmentation on the face and ears are two of the subjectively assessed traits on which much emphasis is placed during selection. The results of this study indicate a favourable relationship between softer faces and reproduction and fleece production. Selection emphasis on softer faces would not have a negative effect on the economically important traits. The same applies for the extent of pigmentation on the face and ears, as no noteworthy genetic correlations between PIGM and any of the other traits analysed, were estimated.

Decreasing fibre diameter and improving crimp definition are two of the most important aspects in the breeding plan of Afrino breeders. At the same time, breeders discriminate strongly against creeping bellies, even to the extent of culling animals superior in terms of the economically important traits. The genetic correlations estimated among fibre diameter, crimp definition and creeping belly indicate that indiscriminate selection against creeping bellies will result in increased fibre diameter and decreased crimp definition. This is clearly illustrated through the genetic trends in fibre diameter, creeping belly and crimp definition in the Carnarvon Afrino flock, where selection for decreased fibre diameter and improved crimp definition lead to the appearance of more creeping belly.

Other unfavourable correlations, in light of the current practice of discriminating against creeping bellies, are the genetic correlations estimated between CBEL and reproduction and body weight at all ages. Animals with higher body weights and ewes with higher reproductive rates also had lower creeping belly scores. The economic implications, in terms of loss of genetic gain in body weight and reproductive rate when selection is done against creeping bellies, are obvious. However, the implication on wool income if less selection emphasis is placed on creeping belly, should be investigated further. Most probably this would be far less detrimental than anticipated, owing to the fact that fleeces with creeping bellies usually are finer, and would, therefore, fetch higher prices. It is proposed that only animals with extreme creeping bellies be culled.

Of the other subjectively assessed fleece traits, evenness of fleece has a negative relationship with reproduction $(-0.50 \pm 0.33)$. This should also be taken into account during selection, where emphasis is placed on the former. However, in practice, much less emphasis is placed on evenness of fleece compared to creeping belly. Other subjectively assessed fleece traits analysed, would not be influenced to any major extent when selection is for increased body weight or reproduction. A similar conclusion, albeit based on phenotypic correlations, was drawn by Olivier et al. (1997) for Merino sheep.

\section{Conclusion}

There is a fine balance between the various production functions that should be kept in mind when constructing and implementing a breeding plan for any sheep breed. This is especially important in dual-purpose sheep breeds where the ewes are expected to produce good quality slaughter lambs, as well as a reasonable amount of good quality fine wool. It is therefore important that selection priorities be based on economic values of the traits. With the exception of two or three traits, the subjectively assessed traits would not be influenced detrimentally when selection is based on the economically important production traits. As far as creeping belly is concerned, more data, especially reproductive data, are needed to quantify the economic implications if less selection pressure is placed against creeping belly. In the meantime, it is proposed that only animals with extreme creeping bellies be culled.

\section{Acknowledgement}

The South African Journal of Animal Science is available online at http://www.sasas.co.za/Sajas.html 
The authors acknowledge the assistance of the technicians at Grootfontein ADI and Carnarvon Experimental Station with the linear assessment of the traits.

\section{References}

Cloete, S.W.P., Olivier, J.J. \& Du Toit, E., 1992. Linear type traits in a Merino flock subjected to selection for increased clean fleece mass and an unselected control flock. S. Afr. J. Anim. Sci. 22, 70-73.

Crook, B.J., Piper, L.R. \& Mayo, O., 1994. Phenotypic associations between fibre diameter variability and greasy wool staple characteristics within Peppin Merino stud flocks. Wool Tech. Sheep Breed. 42, 304318.

Fogarty, N.M., 1995. Genetic parameters for live weight, fat and muscle measurements, wool production and reproduction in sheep: A review. Anim. Breed. Abstr. 63, 101-143.

Fogarty, N.M., Brash, L.D. \& Gilmour, A.R., 1994. Genetic parameters for reproduction and lamb production and their components and live weight, fat depth and wool production in Hyfer sheep. Aust. J. Agric. Res. $45,443-457$.

Gilmour, A.R., Thompson, R, Cullis, B.R. \& Welham, S.J., 1997. ASREML, Biometric Bulletin, 3, NSW, Agriculture, p. 92.

Groenewald, P.G.J., Olivier, J.J. \& Olivier, W.J., 1999. Heritability estimates for Merino sheep obtained from a national progeny test. S. Afr. J. Anim. Sci. 29, 174-178.

Hill, J.A., Hynd, P.I., Ponzoni, R.W., Grimson, R.J., Jaensch, K.S., Kenyon, R.V. \& Penno, N.M., 1997. Skin and follicle characters II. Correlations with objectively measured and subjectively assessed wool characters. Association for the Advancement of Animal Breeding and Genetics, Proc. $12^{\text {th }}$ Conf., Dubbo, NSW, Australia, April 1997, Part 1, 524-529.

Lewer, R.P., Woolaston, R.R. \& Howe, R.R., 1995. Studies on Western Australian Merino sheep. III. Genetic and phenotypic parameter estimates for subjectively assessed and objectively measured traits in ewe hoggets. Aust. J. Agric. Res. 46, 379-388.

Littell, R.C., Freud, R.J., Spector, P.C., 1991. SAS-system for linear models (3rd ed.), SAS Institute. Inc., Cary, North Carolina. pp. 137-198.

Olivier, J.J., Cloete, S.W.P. \& Snyman, M.A., 1997. Relationship between type and production traits in South African Merino sheep. Proc. $35^{\text {th }}$ SASAS congress, Nelspruit, 1-3 July.

Olivier, J. J., Delport, G.J., Erasmus, G.J. \& Eksteen, T.J., 1987. Linear type scoring in Merino sheep. Karoo Agric. 3, 1-4.

Olivier, W.J., Snyman, M.A., Olivier, J.J., Van Wyk, J.B. \& Erasmus, G.J., 2001. Direct and correlated selection responses to selection for total weight of lamb weaned in Merino sheep. S. Afr. J. Anim. Sci. 31, 115121.

Snyman, M.A., Cloete, S.W.P. \& Olivier, J.J., 1998a. Genetic and phenotypic correlations of total weight of lamb weaned with body weight, clean fleece weight and mean fibre diameter in three South African Merino flocks. Livest. Prod. Sci. 55, 157-162.

Snyman, M.A., Erasmus, G.J. \& Van Wyk, J.B., 1995a. Non-genetic factors influencing growth and fleece traits in Afrino sheep. S. Afr. J. Anim. Sci. 25, 70-74.

Snyman, M.A., Erasmus, G.J. \& Van Wyk, J.B., 1998b. The possible genetic improvement of reproduction and survival rate in Afrino sheep using a threshold model. S. Afr. J. Anim. Sci. 28, 120-124.

Snyman, M.A., Erasmus, G.J., Van Wyk, J.B. \& Olivier, J.J., 1995b. Direct and maternal (co)variance components and heritability estimates for body weight at different ages and fleece traits in Afrino sheep. Livest. Prod. Sci. 44, 229-236.

Snyman, M.A., Erasmus, G.J., Van Wyk, J.B. \& Olivier, J.J., 1998c. Genetic and phenotypic correlations among production and reproduction traits in Afrino sheep. S. Afr. J. Anim. Sci. 28, 74-81.

Snyman, M.A., Olivier, J.J., Erasmus, G.J. \& Van Wyk, J.B., 1997. Genetic parameter estimates for total weight of lamb weaned in Afrino and Merino sheep. Livest. Prod. Sci. 48, 111-116.

Swan, A.A., Purvis, I.W., Hansford, K. \& Humphries, W., 1997. The genetics of measured and assessed style in Merino sheep. Association for the Advancement of Animal Breeding and Genetics, Proc. $12^{\text {th }}$ Conf., Dubbo, NSW, Australia, April 1997, Part 1, 153-157. 